\title{
Modification of planned actions
}

Sukhvinder S. Obhi • Shannon Matkovich •

Sam J. Gilbert

Published online: 24 October 2008

(c) Springer-Verlag 2008

\section{Erratum to: Exp Brain Res}

DOI 10.1007/s00221-008-1584-5

In the published original version of the article (page 8, left column, 10th line from top), "N300" should read "P300".

The online version of the original article can be found under doi:10.1007/s00221-008-1584-5.

S. S. Obhi $(\bowtie) \cdot S$. Matkovich Department of Psychology,

Centre for Cognitive Neuroscience,

Wilfrid Laurier University, Waterloo, Canada

e-mail: sobhi@wlu.ca

\section{S. J. Gilbert}

Department of Psychology,

Institute of Cognitive Neuroscience,

University College London, London, UK 